\title{
Stark shifts and transition probabilities in the Ne II spectrum
}

\author{
S. Djeniže $\mathrm{e}^{1,3}$, V. Milosavljević ${ }^{1}$, and M. S. Dimitrijević ${ }^{2}$ \\ 1 Faculty of Physics, University of Belgrade, PO Box 368, Belgrade, Serbia, Yugoslavia \\ 2 Astronomical Observatory, Belgrade, Volgina 7, Serbia, Yugoslavia \\ 3 Hungarian Academy of Science, Budapest, Hungary
}

Received 13 June 2001 / Accepted 2 November 2001

\begin{abstract}
Stark shifts $(d)$ and transition probabilities of the spontaneous emission (Einstein's $A$ values) of forty two singly charged neon (NeII) ion spectral lines have been measured in a linear, low pressure, pulsed arc at $35300 \mathrm{~K}$ electron temperature and $1.83 \times 10^{23} \mathrm{~m}^{-3}$ electron density. Transition probabilities have been obtained using the relative line intensity ratio (RLIR) method. Stark shift values have also been calculated, using the semiclassical perturbation formalism (SCPF). The measured and calculated shift values and the measured $A$ values have been compared to the existing data taken from available data sources.
\end{abstract}

Key words. atomic data - radiation mechanisms: general - methods: laboratory

\section{Introduction}

Atomic data such as Stark widths $(W)$ and shifts $(d)$ and transition probabilities $(A)$ play an important role in the diagnostics and modelling of various cosmic and laboratory plasmas (Griem 1964; Wiese 1968; Rompe \& Steenbeck 1967; Griem 1974; Wiese et al. 1966; Griem 1997). The basic plasma parameters such as electron temperature $(T)$ and density $(N)$ may be obtained on the basis of the known $d$ and $W$ values. However, various optical depths of the emitting plasma may result in selfabsorption influencing the line width value (screening the Stark contribution). Thus, Stark shifts independent of selfabsorption are more reliable and consequently more interesting for diagnostic purposes. On the other hand, various kinetic processes appearing in plasma modelling require reliable knowledge of the $A$ values (Griem 1997; Lesage \& Fuhr 1999; Zeippen 1995). Furthermore, knowledge of the $A$ values gives the possibility to determine the $(B)$ coefficients which characterize the absorption and stimulated emission. These processes are also important in the laser physics and astrophysics.

Neon is the most abundant element in the Universe after $\mathrm{H}, \mathrm{He}, \mathrm{O}$ and $\mathrm{C}$ and it is one of products of hydrogen and helium burning in orderly evolution of stellar interiors (Trimble 1991). After the hydrogen, helium and carbon-burning periods, in massive stars neon burning

Send offprint requests to: V. Milosavljević, e-mail: vladimir@ff.bg.ac.yu starts. Neon also occurs in supernovae ejecta (Thieleman et al. 1986). After the earlier investigation of Ne II Stark shifts (Pretty 1931; Maissel 1959; Mandel'shtam 1962; Mandel'shtam et al. 1963; Mazing \& Vrublevskaya 1962) the first measurements of $d$ values at convenient plasma parameters $(T$ and $N)$ were performed in only one experiment (Purić et al. 1987). In this experiment (Purić et al. 1987) $d$ values of 18 Ne II spectral lines from 13 multiplets were measured at $35000 \mathrm{~K}$ electron temperature and $1.42 \times 10^{23} \mathrm{~m}^{-3}$ electron density.

Unique theoretical calculations, made on the basis of the semiclassical $(G)$ approximation (Griem 1974), are performed up to $T=40000 \mathrm{~K}$ only for seven Ne II multiplets $\left({ }^{4} \mathrm{P} \_{ }^{4} \mathrm{P}^{0},{ }^{4} \mathrm{P} \_{ }^{4} \mathrm{D}^{0}\right.$ and ${ }^{2} \mathrm{P}-2 \mathrm{D}^{0}$ in transition $3 \mathrm{~s}-3 \mathrm{p}$; ${ }^{4} \mathrm{P}^{0} \_4 \mathrm{D},{ }^{2} \mathrm{D}^{0} \_2 \mathrm{~F},{ }^{2} \mathrm{~S}^{0} \_2 \mathrm{P}$ and ${ }^{4} \mathrm{~S}^{0} \_4 \mathrm{P}$ in transition $\left.3 \mathrm{p}-3 \mathrm{~d}\right)$.

We have measured Stark shift values of 42 Ne II spectral lines that belong to 23 multiplets and calculated Stark shift values for 22 multiplets. Shift values of 30 lines were not known before. Measurements were realized at plasma parameters of $T=35300 \mathrm{~K}$ and $N=1.83 \times 10^{23} \mathrm{~m}^{-3}$. Our $N$ value is about $30 \%$ higher than those in the experiment of Purić et al. (1987) giving a higher accuracy of the determined $d$ values. The known semiclassical perturbation formalism (SCPF), updated several times, has been used for the calculations of $d$ values.

Existing measured and calculated NeII $A$ values are collected in a number of articles (Wiese et al. 1966; NIST 2001; Kurucz 2001; Burshtein \& Vujnović 1991; Blackford \& Hibbert 1994; Griesmann et al. 1997; Fischer \& He 1999; Zeippen 1995). Existing transition probability values 
of the spontaneous emission (Einstein's $A$ values) corresponding to the NeII transitions investigated have also been checked using the known relative line intensity ratio (RLIR) method described in Djeniže \& Bukvić (2001). It was found that $32 A$ values of the investigated 41 transitions need a correction.

\section{Experiment}

A modified version of the linear low-pressure pulsed arc (Djeniže et al. 1991; Djeniže et al. 1992; Djeniže et al. 1998; Milosavljević et al. 2000) has been used as an optically thin plasma source. A pulsed discharge was driven in a quartz discharge tube of $5 \mathrm{~mm}$ inner diameter and effective plasma length of $7.2 \mathrm{~cm}$ (Fig. 1 in Djeniže et al. 1991; Djeniže et al. 1998). The tube has end-on quartz windows on the side of the spectrograph. On the opposite side of the electrodes the glass tube was expanded in order to reduce erosion of the glass wall and also sputtering of the electrode material onto the quartz windows. The working gas was pure neon at $133 \mathrm{~Pa}$ filling pressure in the flowing regime. Spectroscopic observations of isolated spectral lines were made along the axis of the discharge tube. A capacitor of $14 \mu \mathrm{F}$ was charged up to $2.5 \mathrm{kV}$. The line profiles were recorded using a step-by-step technique with a photomultiplier (EMI $9789 \mathrm{QB}$ ) and a grating spectrograph (Zeiss PGS-2, reciprocal linear dispersion $0.73 \mathrm{~nm} / \mathrm{mm}$ in the first order) system. The system was calibrated by using an EOA-101 standard lamp located at $40 \mathrm{~cm}$ distance from the spectrograph input slit. The instrumental FWHM of $0.008 \mathrm{~nm}$ was determined by using the narrow spectral lines emitted by the hollow cathode discharge. The recorded profiles of these lines are Gaussian in shape to within $8 \%$ accuracy within the wavelength range of the investigated spectral lines. The spectrograph exit slit $(10 \mu \mathrm{m})$ with the calibrated photomultiplier was micrometrically moved along the spectral plane in small wavelength steps $(0.0073 \mathrm{~nm})$. The averaged photomultiplier signal (five shots at the same spectral range) was digitalized using an oscilloscope, interfaced to a computer. All spectral line profiles were recorded at the same detection conditions. A sample output, as example, is shown in Fig. 1.

Plasma reproducibility was monitored by the Ne II line radiation and by the discharge current (it was found to be within $\pm 3 \%$ ). The discharge characteristics were determined by analyzing the Rogowski coil signal. The values found were: discharge current $=2.95 \mathrm{kA}$, discharge period $=70 \mu \mathrm{s}$, thermal resistance $=0.44 \Omega$, and decrement $=2.6$.

The measured profiles were of the Voigt type due to the convolution of the Lorentz, Stark, and Gaussian profiles with Doppler and instrumental broadening. For the electron density and temperature of our experiments the Lorentz fraction in the Voigt profile was dominant (over $88 \%$ ). Van der Waals and resonance broadening were estimated to be smaller by more than one order of magnitude

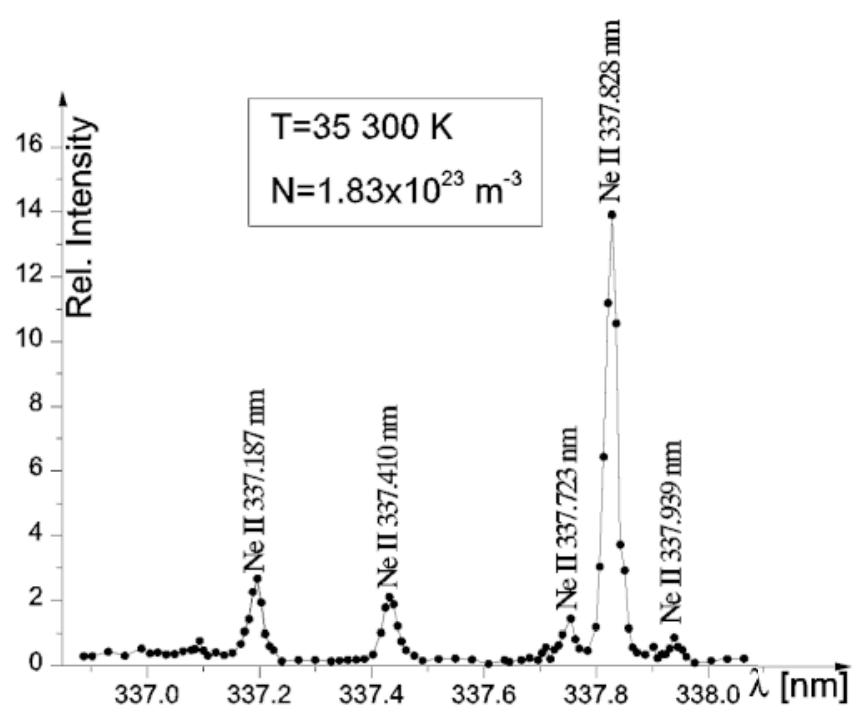

Fig. 1. Recorded spectrum with several investigated Ne II lines.

in comparison to Stark, Doppler and instrumental broadening. The standard deconvolution procedure (Davies \& Vaughan 1963; Milosavljević \& Poparić 2001) was computerized using a least squares algorithm. Total line intensity $(I)$ corresponds to the area under the line profile. One can notice, see Fig. 1, that the investigated spectral lines are well isolated while the continuum is close to the zero value within the same range of wavelengths. These facts are important for accurate determination of the total line intensities and the values are very convenient as they increase the reliability of the results. Great care was taken to minimize the influence of self-absorption on the total line intensity determination. The opacity was checked by measuring relative line intensity $(I)$ ratios within the low lying multiplets (Nos. 1, 2 and 7) in the Ne II spectrum during the decaying plasma. Absence of the self-absorption would cause constant relative line intensity ratio (Djeniže \& Bukvic 2001). This is fullfilled in the case of the low lying multiplets within $\pm 5 \%$ (see Fig. 4). Therefore, the influence of the self-absorption on the total line intensity values for Ne II lines can be neglected.

Basic investigations were made of the electrical and optical characteristics of the part of the discharge channel connecting the narrow linear tube and the electrodes. We have inspected the shape of the discharge using a low current DC discharge. We found that the diameter of the discharge channel outside the narrow tube is about three times wider than in the tube and the discharge channel is bent toward the electrodes. Therefore, the current density is approximately 10 times lower than in the tube. We also found that the brightness of the narrow tube is nearly 10 times higher than outside the tube. In the pulsed regime the shape of the discharge was checked photographically and we found that the shape does not change with respect to that of the DC discharge. Taking into account these measurements we estimated that the density of the radiation coming from outside the narrow tube is on average at 
least 5 to 10 times lower than the radiation density coming from the tube. We also estimated that the length of the discharge outside the tube, contributing to the light captured by the spectrograph, does not exceed $10 \mathrm{~mm}$ i.e. it is 7 times shorter than the tube. Therefore, the overall contribution of the light coming from the discharge outside the narrow tube is $1.5 \%-3 \%$ of the total intensity. Thus, the line profile is "spoiled" by the same amount by an unknown profile coming from the part which connects the linear tube to the electrodes. Fluctuations of the light intensity in the shot-by-shot technique that we have applied are of the order of $3 \%-5 \%$ if the lines under consideration originate from buffer gas, or up to $20 \%$ if the spectral lines originate from sputtered material. So it can be concluded that the contribution of the "cold" plasma is masked by the uncertainty caused by fluctuations of the plasma source. The "effective length" is related to the interferometric measurements. It is a few percent longer than the geometrical length of the tube due to the fact that plasma is not restricted just to the area inside the narrow tube. The value of the "effective length" is estimated on an empirical basis. The effective plasma length used can be treated as optically thin for the NeII lines under investigation.

The plasma parameters were determined using standard diagnostic methods (Griem 1964; Wiese 1968; Rompe $\&$ Steenbeck 1967). Thus, the electron temperature $(T)$ was determined from the Boltzmann plot of the relative intensities of NeII spectral lines. First, this was done for 14 NeII lines $(331.98 \mathrm{~nm}, 336.06 \mathrm{~nm}, 337.18 \mathrm{~nm}$, $341.48 \mathrm{~nm}, 341.69 \mathrm{~nm}, 341.77 \mathrm{~nm}, 350.36 \mathrm{~nm}, 356.83 \mathrm{~nm}$, $366.41 \mathrm{~nm}, 369.42 \mathrm{~nm}, 429.04 \mathrm{~nm}, 439.19 \mathrm{~nm}, 440.93 \mathrm{~nm}$ and $441.32 \mathrm{~nm}$ ) within an energy interval of $7.13 \mathrm{eV}$ for corresponding upper-levels, assuming the existence of local thermodynamic equilibrium (LTE), according to the criterion in Griem (1964). All necessary atomic data were taken from Wiese et al. (1966) and Striganov \& Sventickij (1966). The electron temperature obtained at $17 \mu$ s after the beginning of the discharge was $34500 \mathrm{~K} \pm 6 \%$. Second, it was done for all investigated (41 Ne II) lines, within an energy interval of $7.45 \mathrm{eV}$, using our new $A$ values. At $17 \mu \mathrm{s}$ after the beginning of the discharge we found an electron temperature of $35300 \mathrm{~K} \pm 3 \%$. It turns out that the fitting correlation factor was excellent (0.997).

As an example, the Boltzmann plot obtained at $17 \mu \mathrm{s}$ after the beginning of the discharge is presented in Fig. 2. The electron temperature decay is presented in Fig. 3, together with the electron density $(N)$ decay. The latter was measured using the well-known single laser interferometry technique (Ashby et al. 1965) for the $632.8 \mathrm{~nm}$ $\mathrm{He}-\mathrm{Ne}$ laser wavelength with an estimated error of $\pm 4 \%$ (this corresponds to $1 / 4$ fringe uncertainty on a total of 7 fringes). The electron density decay is presented, also, in Fig. 3. Taking into account the temporal dependence of $T$ and $N$ and the criteria for the existence of LTE (Griem 1964; Hey 1976), we can conclude that relevant Ne II ion level populations remain in LTE up to $50 \mu$ s after the beginning of the discharge.

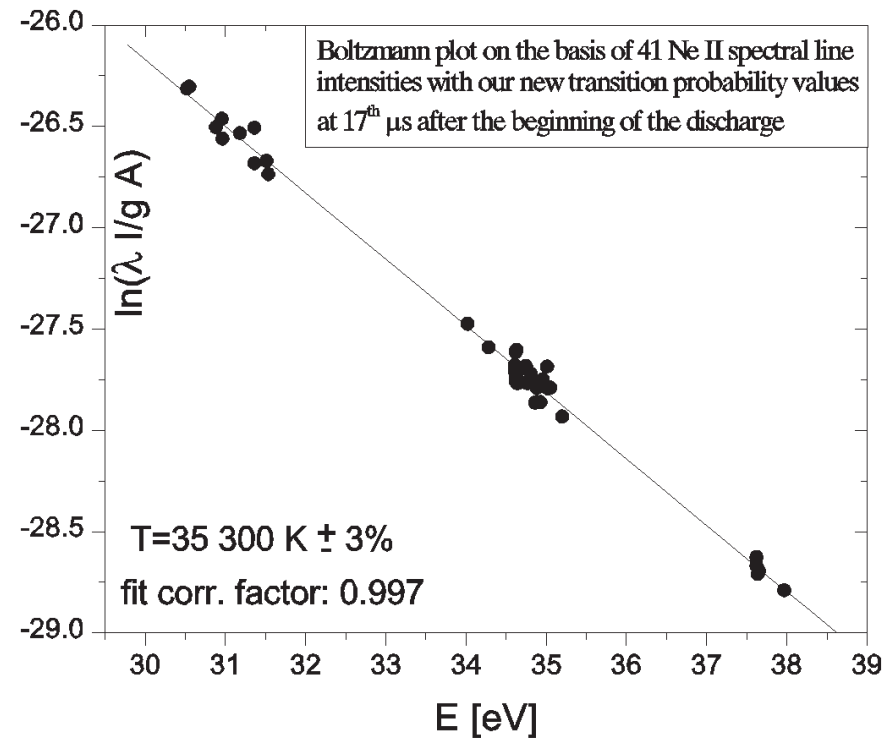

Fig. 2. Boltzmann plot.

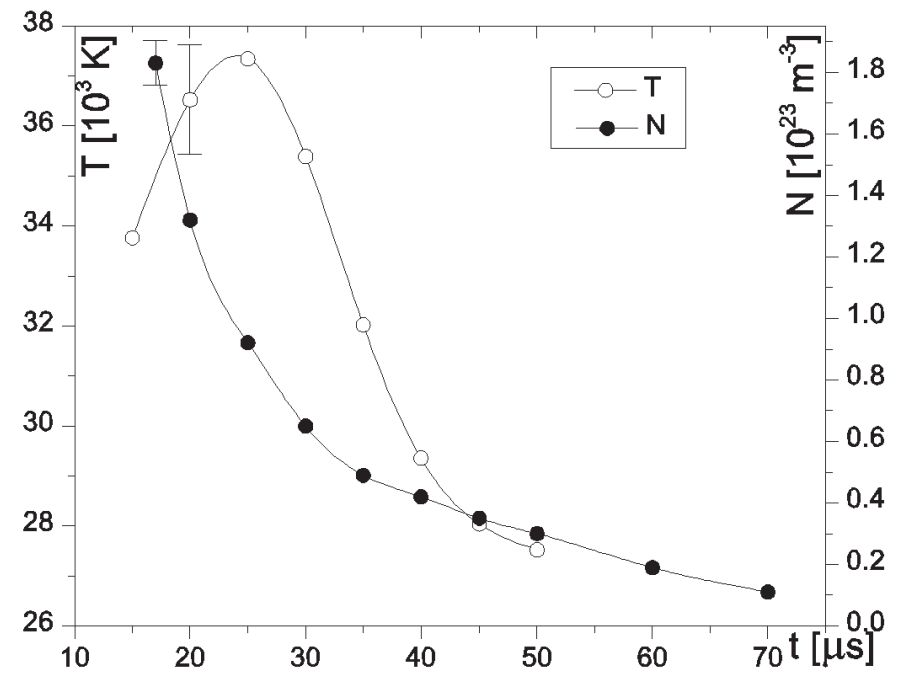

Fig. 3. Temporal evolution of the electron temperature $(T)$ and electron density $(N)$ during plasma decay.

At $17 \mu$ s after the beginning of the discharge, when the shifted Ne II spectral line profile center positions were monitored, the electron temperature found was $35300 \mathrm{~K}$ and the electron density $1.83 \times 10^{23} \mathrm{~m}^{-3}$.

\subsection{Stark shift measurements}

The Stark shifts were measured relative to the unshifted spectral lines emitted by the same plasma (Milosavljević et al. 2000 and references therein). The Stark shift of $A$ spectral line can be measured experimentally by evaluating the position of the spectral line center $\left(X_{\mathrm{c}}\right)$ recorded at two different electron density values during plasma decay. In principle, the method requires recording the spectral line profile at the high electron density $\left(N_{1}\right)$ that causes an appreciable shift and then later when the electron concentration has dropped to a value $\left(N_{2}\right)$ lower by at least 
an order of magnitude. The difference of the line center positions in these two cases is $\Delta d$, so that the shift $d_{1}$ at the higher electron density $N_{1}$ is:

$d_{1}=N_{1} \cdot \Delta d /\left(N_{1}-N_{2}\right)$.

The Stark shift data were corrected for the electron temperature decay (Popović et al. 1992). Stark shift data are determined with $\pm 0.0008 \mathrm{~nm}$ error at a given $N$ and $T$.

\subsection{Transition probability measurements}

Transition probabilities of spontaneous emission of 41 transitions in the Ne II spectrum have been obtained using the RLIR method (Djeniže \& Bukvić 2001). The total line intensities $(I)$ have been measured with high accuracy $(3 \%-5 \%)$ using the step-by-step technique (described above) for the line profiles recording. In the case when plasma remains at LTE the well-known formula (Griem 1974):

$\left(I_{1} / I_{2}\right)_{\mathrm{EXP}}=\left(A_{1} g_{1} \lambda_{2} / A_{2} g_{2} \lambda_{1}\right) \exp \left(\Delta E_{21} / k T\right)$,

can be used for a comparison between measured relative line intensity ratios and corresponding calculated values, taking into account the validity of the Boltzmann distribution for the population of the excited levels in emitters. In this expression $I$ denotes the measured relative intensity, $\lambda$ the wavelength of the transition, $A$ the transition probability of the spontaneous emission, $E$ the excitation energy from the ground energy level, and $g$ the corresponding statistical weight. $T$ is the electron temperature of the plasma in LTE and $k$ is the Boltzmann constant. In the case where the spectral lines to be compared belong to the same multiplet, Eq. (2) can be re-written in the form:

$\left(I_{1} / I_{2}\right)_{\mathrm{EXP}}=A_{1} g_{1} / A_{2} g_{2}$,

due to the very small difference between excitation energies and wavelengths related to the compared lines. Eq. (3) provides a possibility for checking the existing $A$ values associated with the transitions within a multiplet.

We found that the experimental ratios are constant (within $\approx \pm 5 \%$ ) within the same multiplet during the plasma decay. This offers the possibility to use the comparison between measured and calculated relative line intensity ratios as a method (Djeniže \& Bukvić 2001) for estimating the transition probabilities relative to the $A$ value selected as reference.

The choice of the $A$ reference value is important, but it is not crucial. In fact, the information contained in the ratios of relative line intensities is essential. In this paper we have taken the transition probabilities of the most intensive lines ( $333.487 \mathrm{~nm}$ and $303.448 \mathrm{~nm}$ ) as the reference values. There are two practical reasons for such a choice. First, the transition probability values for these lines have remained unchanged for many years in NIST (NBS) (NIST 2001) and in the tables in Wiese et al. (1966). Second, due to their high intensity, measurements related to these lines are most reliable. Using the Eqs. (2) and (3) we found that 32 of the existing $A$ values (NIST) in the investigated Ne II transitions need corrections which are, in most of the cases, within the given uncertainties (NIST) of these lines.

\section{Method of calculation}

The semiclassical perturbation formalism, as well as the corresponding computer code (Dimitrijević \& SahalBréchot 1996a,b), have been updated and optimized several times (Sahal-Bréchot 1974; Fleurier et al. 1977; Dimitrijević \& Sahal-Bréchot 1984; Dimitrijević et al. 1991; Dimitrijević \& Sahal-Bréchot 1996b). The calculation procedure, with a discussion of updating and validity criteria, has been briefly reviewed (e.g. in Dimitrijević \& Sahal-Bréchot 1996a,b), so that only the basic details of the calculations will be presented here. The Stark full width $(W)$ at the intensity half maximum (FWHM) and the shift $(d)$ of an isolated spectral line may be expressed as (Dimitrijević \& Sahal-Bréchot 1996a,b; Fleurier et al. 1977)

$$
\begin{gathered}
W=N \int v f(v) \mathrm{d} v\left(\sum_{i^{\prime} \neq i} \sigma_{i i^{\prime}}(v)\right. \\
\left.+\sum_{f^{\prime} \neq f} \sigma_{f f^{\prime}}(v)+\sigma_{\mathrm{el}}\right)+W_{\mathrm{R}} \\
d=N \int v f(v) \mathrm{d} v \int_{R_{3}}^{R_{\mathrm{D}}} 2 \pi \rho \mathrm{d} \rho \sin 2 \phi_{p},
\end{gathered}
$$

where $N$ is the electron density, $f(v)$ is the Maxwellian velocity distribution function for electrons, $\rho$ denotes the impact parameter of the incoming electron, $i$ and $f$ denote the initial and final atomic energy levels, and $i^{\prime}, f^{\prime}$ their corresponding perturbing levels, while $W_{\mathrm{R}}$ gives the contribution of the Feshbach resonances (Fleurier et al. 1977). The inelastic cross section $\sigma_{j, j^{\prime}}(v), j=i, f$ can be expressed by an integral over the impact parameter of the transition probability $P_{j j^{\prime}}(\rho, v)$ as

$\sum_{j^{\prime} \neq j} \sigma_{j j^{\prime}}(v)=\frac{1}{2} \pi R_{1}^{2}+\int_{R_{1}}^{R_{\mathrm{D}}} \sum_{j \neq j^{\prime}} P_{j j^{\prime}}(\rho, v), j=i, f$

and the elastic cross section is given by

$\sigma_{\mathrm{el}}=2 \pi R_{2}^{2}+\int_{R_{2}}^{R_{\mathrm{D}}} 8 \pi \rho \mathrm{d} \rho \sin ^{2} \delta$

$\delta=\left(\phi_{\mathrm{p}}^{2}+\phi_{\mathrm{q}}^{2}\right)^{1 / 2}$.

The phase shifts $\phi_{\mathrm{p}}$ and $\phi_{\mathrm{q}}$ due respectively to the polarization potential $\left(r^{-4}\right)$ and to the quadripolar potential $\left(r^{-3}\right)$, are given in Sect. 3 of Chapter 2 in Sahal-Bréchot (1969a). $R_{\mathrm{D}}$ is the Debye radius. All the cut-offs $R_{1}, R_{2}$, 
$R_{3}$ are described in Sect. 1 of Chapter 3 in Sahal-Bréchot (1969b). For electrons hyperbolic paths due to the attractive Coulomb force were used, while for perturbing ions the paths are different since the force is repulsive. The formulae for the ion-impact widths and shifts are analogous to Eqs. (4)-(6), without the resonance contribution to the width. The difference in calculation of the corresponding transition probabilities and phase shifts as functions of the impact parameter in Eqs. (5)-(6) is in the ion perturber trajectories which are influenced by the repulsive Coulomb force instead of an attractive one as for electrons.

Atomic energy levels not existing (or revised) in (Moore 1971; Bashkin \& Stoner 1978) have been taken in (Quinet et al. 1994). It should be mentioned that the Ne II spectrum is not well determined experimentally so that the set of experimental perturbing atomic energy levels needed for a semiclassical perturbation method calculation with the usual average accuracy of $\pm 30 \%$, is not complete.

\section{Results}

\subsection{Stark shift}

The results of the measured Stark shift $\left(d_{\mathrm{m}}\right)$ values at electron temperature $T=35300 \mathrm{~K}$ and electron density $1.83 \times 10^{23} \mathrm{~m}^{-3}$ are shown in Table 1 .

Our calculated Stark shift values are presented in Table 2.

\subsection{Transition probabilities}

We have monitored the ratios $\left(I_{1} / I_{2}\right)$ ExP for spectral lines that belong to the same multiplet in a wide range of the decaying plasma up to the moment when the line intensity maximum dropped down to $8 \%$ of its maximal value. We have found that these experimental ratios are constant to within $\pm 5 \%$ during the plasma decay. This suggests that the comparison between the measured and calculated relative line intensity ratios can be used as a method for estimating the transition probabilities relative to the selected reference $A$ values. We suppose that there is at least one pair of lines, belonging to the same multiplet, for which measured and calculated relative line intensity ratios are in agreement (to within the accuracy of the measurements) during the whole plasma decay period. If such agreement really exist one can accept these lines, with the corresponding transition probabilities, as the reference lines. Among the lines that we have investigated such behavior is found for the $333.487 \mathrm{~nm}$ and $332.716 \mathrm{~nm}$ lines in multiplet No. 2 and for the $303.448 \mathrm{~nm}$ and $303.773 \mathrm{~nm}$ lines in multiplet No. 8. These facts allow us to conclude that the existing transition probability values of the strong $333.487 \mathrm{~nm}$ and $303.448 \mathrm{~nm}$ Ne II lines can be used as reference $A$ values.

As an example, relative line intensity ratios measured for the lines within the same multiplet, as an example, are presented in the Fig. 4.

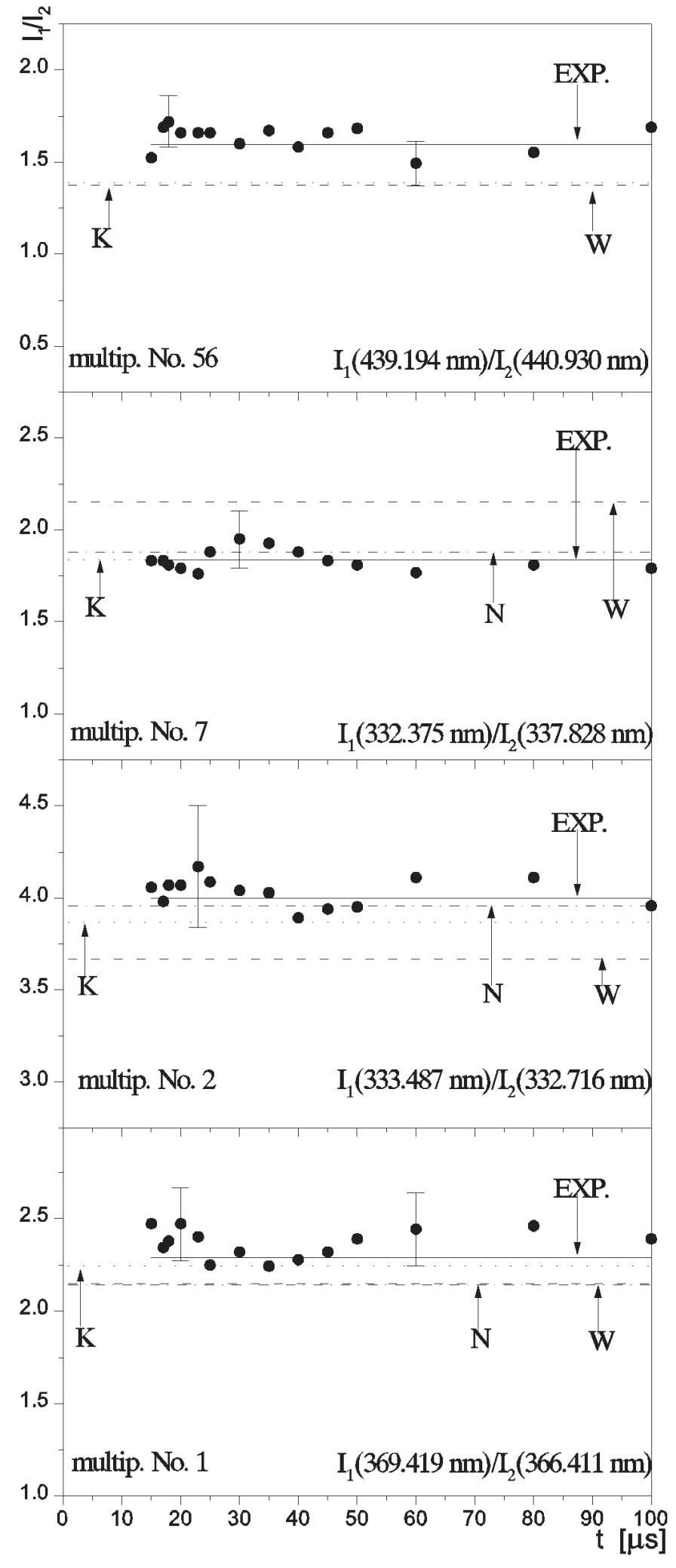

Fig. 4. Relative line intensity ratios $\left(I_{1} / I_{2}\right)$ within the multiplets. - our experimental values during the plasma decay. Theoretical values (Eq. (3)): (- - -) W, from Wiese et al. (1966); (- - -) N, from NIST (2001); ( . .) K, from Kurucz (2001) and (-) EXP, calculated with our experimentally obtained $A$ values from Table 1 . The error bars represent $\pm 8 \%$ uncertainties. 
Table 1. Our measured Stark shift $\left(d_{\mathrm{m}}\right)$ values for the Ne II spectral lines at $35300 \mathrm{~K}$ electron temperature and $1.83 \times 10^{23} \mathrm{~m}^{-3}$ electron density. Positive shift is toward the red. $A_{\exp }\left(\right.$ in $10^{8} \mathrm{~s}^{-1}$ ) represent our measured transition probability values. $A_{\mathrm{W}}$, $A_{\mathrm{N}}, A_{\mathrm{K}}, A_{\mathrm{GMW}}$ and $A_{\mathrm{BV}}$ denote values taken from Wiese et al. (1966), NIST (2001), Kurucz (2001), Griesmann et al. (1997) and Burshtein \& Vujnović (1991), respectively (also in $10^{8} \mathrm{~s}^{-1}$ ).

\begin{tabular}{|c|c|c|c|c|c|c|c|c|c|c|c|}
\hline Transition & Multiplet & $\lambda(\mathrm{nm})$ & $E(\mathrm{eV})$ & $g$ & $d_{\mathrm{m}}(\mathrm{pm})$ & $A_{\exp }$ & $A_{\mathrm{W}}$ & $A_{\mathrm{N}}$ & $A_{\mathrm{K}}$ & $A_{\mathrm{GMW}}$ & $A_{\mathrm{BV}}$ \\
\hline \multirow[t]{10}{*}{$3 \mathrm{~s}-3 \mathrm{p}$} & ${ }^{4} \mathrm{P}-{ }^{4} \mathrm{P}^{0}$ & 369.419 & 30.52 & 6 & -0.7 & $1.13 \pm 10 \%$ & 0.96 & 1.0 & 1.002 & 0.947 & 0.870 \\
\hline & (1) & 366.411 & 30.55 & 4 & -0.2 & $0.74 \pm 10 \%$ & 0.67 & 0.70 & 0.6822 & 0.553 & 0.560 \\
\hline & ${ }^{4} \mathrm{P}-{ }^{4} \mathrm{D}^{0}$ & 333.487 & 30.88 & 8 & -0.6 & $1.80 \pm 10 \%$ & 1.8 & 1.8 & 1.839 & & \\
\hline & (2) & 336.063 & 30.96 & 4 & 0.0 & $0.90 \pm 10 \%$ & 0.73 & 0.82 & 0.8298 & & \\
\hline & & 332.716 & 30.95 & 4 & -0.8 & $0.90 \pm 10 \%$ & 0.98 & 0.91 & 0.9499 & & \\
\hline & ${ }^{4} \mathrm{P}-{ }^{4} \mathrm{~S}^{0}$ & 300.166 & 31.36 & 4 & -0.8 & $0.80 \pm 16 \%$ & 0.78 & 0.87 & 0.8853 & 0.763 & 0.690 \\
\hline & (4) & 302.886 & 31.36 & 4 & 0.0 & $0.61 \pm 16 \%$ & 0.57 & 0.47 & 0.4669 & 0.420 & 0.420 \\
\hline & $\begin{array}{c}{ }^{2} \mathrm{P}-{ }^{2} \mathrm{D}^{0} \\
(5)\end{array}$ & 372.708 & 31.18 & 4 & -2.5 & $1.26 \pm 16 \%$ & 1.0 & 0.98 & 1.146 & 0.870 & 0.800 \\
\hline & ${ }^{2} \mathrm{P}-{ }^{2} \mathrm{P}^{0}$ & 332.375 & 31.51 & 4 & 0.0 & $1.45 \pm 10 \%$ & 1.4 & 1.6 & 1.408 & 1.350 & 1.280 \\
\hline & (7) & 337.828 & 31.53 & 2 & 0.0 & $1.58 \pm 10 \%$ & 1.3 & 1.7 & 1.533 & 1.620 & 1.350 \\
\hline \multirow[t]{2}{*}{$3 s^{\prime}-3 p^{\prime}$} & $\begin{array}{c}{ }^{2} \mathrm{D}^{-2} \mathrm{~F}^{0} \\
(9)\end{array}$ & 356.853 & 34.02 & 8 & -0.6 & $2.36 \pm 16 \%$ & 1.3 & 1.4 & 1.534 & & \\
\hline & $\begin{array}{c}{ }^{2} \mathrm{D}^{-2} \mathrm{P}^{0} \\
(10)\end{array}$ & 331.975 & 34.28 & 2 & -1.0 & $2.10 \pm 16 \%$ & 1.7 & 1.6 & 1.701 & & \\
\hline \multirow[t]{20}{*}{$3 p-3 d$} & ${ }^{4} \mathrm{P}^{0}-{ }^{4} \mathrm{D}$ & 303.448 & 34.61 & 8 & 0.0 & $3.10 \pm 10 \%$ & 3.1 & 3.1 & 2.797 & 2.700 & \\
\hline & (8) & 302.704 & 34.62 & 6 & 0.4 & $1.44 \pm 10 \%$ & 1.51 & 1.4 & 1.33 & & \\
\hline & & 303.773 & 34.63 & 4 & 0.2 & $2.10 \pm 10 \%$ & 2.0 & 2.1 & 1.848 & & \\
\hline & ${ }^{4} \mathrm{D}^{0} \_{ }^{4} \mathrm{D}$ & 332.920 & 34.61 & 8 & 0.8 & $1.00 \pm 16 \%$ & 0.87 & 0.88 & 0.9039 & 0.858 & \\
\hline & (12) & 335.790 & 34.62 & 6 & 1.4 & $0.66 \pm 16 \%$ & 0.55 & 0.50 & 0.5541 & & \\
\hline & & 332.029 & 34.62 & 6 & - & $0.40 \pm 16 \%$ & 0.13 & 0.21 & 0.2106 & & \\
\hline & & 337.410 & 34.63 & 4 & 3.1 & $0.38 \pm 18 \%$ & 0.38 & 0.30 & 0.3432 & & \\
\hline & & 336.289 & 34.64 & 2 & 0.9 & - & & & & & \\
\hline & & 337.939 & 34.64 & 2 & 2.5 & $0.31 \pm 20 \%$ & 0.35 & 0.30 & 0.3127 & & \\
\hline & ${ }^{2} \mathrm{D}^{0}{ }^{2} \mathrm{~F}$ & 341.771 & 34.75 & 8 & 2.4 & $1.65 \pm 16 \%$ & 2.0 & 1.6 & 1.457 & & \\
\hline & $(20)$ & 341.482 & 34.81 & 6 & 3.1 & $0.70 \pm 16 \%$ & 0.41 & 0.018 & 0.3972 & & \\
\hline & $\begin{array}{c}{ }^{2} \mathrm{D}^{0}{ }^{2}{ }^{2} \mathrm{D} \\
(21)\end{array}$ & 341.682 & 34.75 & 6 & 4.2 & $0.85 \pm 16 \%$ & 0.67 & 0.64 & 0.3877 & & \\
\hline & $\begin{array}{c}{ }^{2} \mathrm{D}^{0}-{ }^{4} \mathrm{P} \\
(22)\end{array}$ & 337.187 & 34.86 & 6 & 0.7 & $0.35 \pm 18 \%$ & 0.12 & 0.22 & 0.7586 & & \\
\hline & $\begin{array}{c}{ }^{2} \mathrm{~S}^{0}-^{2} \mathrm{P} \\
(28)\end{array}$ & 350.361 & 34.88 & 2 & 0.0 & $2.55 \pm 16 \%$ & 1.9 & 2.0 & 2.207 & & \\
\hline & ${ }^{2} \mathrm{P}^{0}-^{2} \mathrm{P}$ & 369.709 & 34.88 & 2 & - & $0.29 \pm 18 \%$ & 0.34 & 0.28 & 0.2495 & & \\
\hline & $(41)$ & 362.806 & 34.93 & 4 & 3.5 & $0.40 \pm 18 \%$ & 0.57 & 0.60 & 0.5158 & & \\
\hline & ${ }^{4} \mathrm{~S}^{0}-{ }^{2} \mathrm{D}$ & 365.993 & 34.75 & 6 & 4.0 & $0.14 \pm 18 \%$ & 0.11 & 0.067 & 0.0629 & & \\
\hline & (33) & 363.275 & 34.77 & 4 & 6.9 & $0.23 \pm 18 \%$ & 0.09 & 0.13 & 0.3903 & & \\
\hline & $\begin{array}{c}{ }^{4} \mathrm{~S}^{0}-{ }^{4} \mathrm{~F} \\
(31)\end{array}$ & 357.126 & 34.83 & 6 & 2.9 & $0.84 \pm 16 \%$ & 0.43 & 0.63 & 0.9687 & & \\
\hline & $\begin{array}{c}{ }^{4} \mathrm{~S}^{0}-{ }^{4} \mathrm{P} \\
(34)\end{array}$ & 356.584 & 34.84 & 4 & 2.2 & $0.84 \pm 16 \%$ & 0.82 & 0.62 & 0.1895 & & \\
\hline $3 \mathrm{p}^{\prime}-3 \mathrm{~d}^{\prime}$ & ${ }^{2} \mathrm{P}^{0}-^{2} \mathrm{D}$ & 333.612 & 37.97 & 4 & 1.3 & $1.20 \pm 16 \%$ & - & 1.10 & 0.9316 & & \\
\hline \multirow[t]{5}{*}{$3 p-4 s$} & ${ }^{2} \mathrm{P}^{0}{ }^{2} \mathrm{P}$ & 337.728 & 35.20 & 2 & 5.4 & $0.64 \pm 20 \%$ & - & - & 0.6851 & & \\
\hline & ${ }^{4} \mathrm{D}^{0}-{ }^{4} \mathrm{P}$ & 303.965 & 34.96 & 6 & 6.4 & $0.93 \pm 16 \%$ & - & - & 1.319 & 0.609 & \\
\hline & & 303.598 & 35.01 & 4 & 2.0 & $1.29 \pm 16 \%$ & - & - & 1.04 & & \\
\hline & & 303.079 & 35.05 & 2 & - & $1.45 \pm 16 \%$ & - & - & 0.8506 & & \\
\hline & ${ }^{4} \mathrm{P}^{0}-{ }^{4} \mathrm{P}$ & 278.002 & 35.01 & 4 & - & $0.14 \pm 20 \%$ & - & - & 0.1299 & & \\
\hline \multirow[t]{4}{*}{$3 d-4 f$} & ${ }^{4} \mathrm{~F}-{ }^{4} \mathrm{~F}^{0}$ & 439.194 & 37.62 & 10 & -7.2 & $2.68 \pm 10 \%$ & 2.2 & 0.24 & 2.395 & & \\
\hline & (56) & 440.930 & 37.65 & 8 & -5.5 & $2.10 \pm 10 \%$ & 2.0 & - & 2.163 & & \\
\hline & ${ }^{4} \mathrm{~F}-{ }^{4} \mathrm{G}^{0}$ & 429.040 & 37.62 & 12 & -3.3 & $2.56 \pm 10 \%$ & 2.5 & 2.5 & 2.448 & & \\
\hline & $(57)$ & 441.320 & 37.64 & 6 & -14.9 & $2.25 \pm 10 \%$ & 2.0 & 2.0 & 1.477 & & \\
\hline
\end{tabular}

Our measured transition probability values $\left(A_{\exp }\right)$ are presented in Table 1 together with $A$ values taken from various theoretical (Wiese et al. 1966; NIST 2001; Kurucz 2001) and experimental data sources (Burshtein \& Vujnović 1991; Griesmann et al. 1997).

\section{Discussion}

\subsection{Stark shift}

In order to make easier the comparison between measured and calculated Stark shift values, the theoretical Stark 
Table 2. Electron Stark shift ( $d$ in pm) calculated by using the semiclassical perturbation formalism (SCPF) [Eqs. (4)-(6)] for the Ne II spectral lines at $10^{23} \mathrm{~m}^{-3}$ electron density and for electron temperatures from $5000 \mathrm{~K}$ up to $100000 \mathrm{~K}$. $\bar{\lambda}$ is the mean wavelength in the multiplet. Positive shift is toward the red.

\begin{tabular}{|c|c|c|c|c|c|c|c|c|}
\hline Transition & $\bar{\lambda}(\mathrm{nm})$ & $T\left(10^{4} \mathrm{~K}\right):$ & 0.5 & 1 & 2 & 3 & 5 & 10 \\
\hline $3 \mathrm{~s}{ }^{4} \mathrm{P}-3 \mathrm{p}{ }^{4} \mathrm{P}^{0}$ & 372.51 & & 0.003 & -0.365 & -0.480 & -0.432 & -0.543 & -0.455 \\
\hline $3 \mathrm{~s}{ }^{4} \mathrm{P}-3 \mathrm{p}{ }^{4} \mathrm{D}^{0}$ & 334.33 & & -0.035 & -0.136 & -0.187 & -0.178 & -0.216 & -0.189 \\
\hline $3 \mathrm{~s}{ }^{4} \mathrm{P}-3 \mathrm{p}{ }^{4} \mathrm{~S}^{0}$ & 298.83 & & -0.039 & 0.021 & 0.052 & 0.049 & 0.065 & 0.037 \\
\hline $3 \mathrm{~s}^{2} \mathrm{P}-3 \mathrm{p}{ }^{2} \mathrm{D}^{0}$ & 371.41 & & -0.113 & -0.287 & -0.394 & -0.379 & -0.455 & -0.381 \\
\hline $3 \mathrm{~s}{ }^{2} \mathrm{P}-3 \mathrm{p}^{2} \mathrm{P}^{0}$ & 334.27 & & -0.107 & -0.058 & -0.047 & -0.032 & -0.036 & -0.060 \\
\hline $3 s^{\prime 2} \mathrm{D}-3 \mathrm{p}^{\prime}{ }^{2} \mathrm{~F}^{0}$ & 357.21 & & -0.128 & -0.246 & -0.332 & -0.308 & -0.377 & -0.321 \\
\hline $3 \mathrm{~s}^{\prime 2} \mathrm{D}-3 \mathrm{p}^{\prime}{ }^{2} \mathrm{P}^{0}$ & 333.78 & & -0.056 & -0.113 & -0.141 & -0.131 & -0.158 & -0.150 \\
\hline $3 p{ }^{4} \mathrm{P}^{0}-3 \mathrm{~d}{ }^{4} \mathrm{D}$ & 304.01 & & 1.66 & 0.987 & 0.937 & 0.968 & 1.04 & 0.869 \\
\hline $3 p^{4} D^{0}-3 d{ }^{4} D$ & 335.26 & & 0.820 & 0.879 & 0.860 & 0.964 & 1.01 & 0.864 \\
\hline $3 \mathrm{p}^{2} \mathrm{D}^{0}-3 \mathrm{~d}{ }^{4} \mathrm{~F}$ & 342.15 & & 2.51 & 1.45 & 1.34 & 1.43 & 1.49 & 1.27 \\
\hline $3 \mathrm{p}^{2} \mathrm{D}^{0}-3 \mathrm{~d}^{2} \mathrm{~F}$ & 337.56 & & 2.45 & 1.42 & 1.30 & 1.38 & 1.45 & 1.24 \\
\hline $3 p^{2} D^{0}-3 d^{2} D$ & 343.23 & & 0.760 & 0.797 & 0.782 & 0.892 & 0.975 & 0.828 \\
\hline $3 \mathrm{p}^{2} \mathrm{D}^{0}-3 \mathrm{~d}{ }^{4} \mathrm{P}$ & 335.26 & & 2.81 & 1.70 & 1.53 & 1.57 & 1.63 & 1.40 \\
\hline $3 \mathrm{p}^{2} \mathrm{~S}^{0}-3 \mathrm{~d}^{2} \mathrm{P}$ & 347.31 & & 1.47 & 1.36 & 1.22 & 1.36 & 1.42 & 1.26 \\
\hline $3 \mathrm{p}^{2} \mathrm{P}^{0}-3 \mathrm{~d}{ }^{2} \mathrm{P}$ & 365.18 & & 1.30 & 1.24 & 1.12 & 1.30 & 1.35 & 1.23 \\
\hline $3 p^{4} S^{0}-3 d{ }^{2} D$ & 365.00 & & 0.526 & 0.573 & 0.507 & 0.674 & 0.709 & 0.644 \\
\hline $3 p{ }^{4} S^{0}-3 d{ }^{4} F$ & 363.78 & & 1.12 & 1.13 & 1.05 & 1.23 & 1.25 & 1.13 \\
\hline $3 p{ }^{4} S^{0}-3 d{ }^{4} P$ & 356.00 & & 6.79 & 4.40 & 2.46 & 2.61 & 2.17 & 1.58 \\
\hline $3 \mathrm{p}^{\prime}{ }^{2} \mathrm{P}^{0}-3 \mathrm{~d}^{\prime 2} \mathrm{P}$ & 342.27 & & 0.871 & 0.883 & 0.826 & 0.966 & 1.01 & 0.850 \\
\hline $3 \mathrm{p}^{2} \mathrm{P}^{0}-4 \mathrm{~s}^{2} \mathrm{P}$ & 341.23 & & 27.3 & 21.0 & 15.7 & 14.4 & 11.9 & 9.32 \\
\hline $3 p^{4} D^{0}-4 s{ }^{4} P$ & 304.53 & & 22.2 & 17.1 & 12.9 & 11.7 & 9.68 & 7.61 \\
\hline $3 \mathrm{p}{ }^{4} \mathrm{P}^{0}-4 \mathrm{~s}{ }^{4} \mathrm{P}$ & 278.52 & & 19.0 & 14.7 & 11.3 & 10.1 & 8.46 & 6.58 \\
\hline
\end{tabular}

shift dependence on the electron temperature together with the values of the other authors and our experimental results at an electron density of $10^{23} \mathrm{~m}^{-3}$ are presented graphically in Fig. 5.

Generally, we have obtained very small shift values. Both, experimental and measured $d$ values, are below of one pm, within our experimental accuracy $( \pm 0.8 \mathrm{pm})$. Our measured and calculated $d$ values have the same sign (see Fig. 5, Tables 1 and 2).

Stark shifts corresponding to the $3 \mathrm{p}-3 \mathrm{~d}$ and $3 \mathrm{p}-4 \mathrm{~s}$ transition arrays have finite and positive values. Measured shift values corresponding to the $3 \mathrm{~d}-4 \mathrm{f}$ transition are negative and confirm the earlier obtained sign in Purić et al. (1987). Our calculated (SCPF) $d$ values are smaller than those from Griem (1974), by up to a factor 6. Moreover, our calculated $d$ values have negative signs in the case of the lines that belong to the $3 \mathrm{~s}-3 \mathrm{p}$ transition, contrary to the positive $d$ values predicted in Griem (1974). These discrepancies in the sign of $d$ and their magnitude can be explained taking into account the new atomic energy levels and differences in the theoretical methods.

Satisfactory agreement exists among our measured and calculated $d$ values in the case of the lines that belong to the $3 \mathrm{p}-3 \mathrm{~d}$ transition. Earlier measured $3 \mathrm{p}-3 \mathrm{~d}$ shift values (Purić et al. 1987) also agree with our calculated values.

It should be pointed out that we have not performed calculations of $d$ values belonging to lines in the $3 \mathrm{~d}-4 \mathrm{f}$ transition because of the incompleteness of the set of the experimentally determined perturbing energy levels.
The large theoretical $d$ values for $3 \mathrm{p}^{2} \mathrm{P}^{0}-4 \mathrm{~s}{ }^{2} \mathrm{P}$, $3 \mathrm{p}{ }^{4} \mathrm{D}^{0}-4 \mathrm{~s}{ }^{4} \mathrm{P}$ and $3 \mathrm{p}{ }^{4} \mathrm{P}^{0}-4 \mathrm{~s}{ }^{4} \mathrm{P}$ multiplets are due to close $4 \mathrm{p}^{2} \mathrm{P}^{0}$ and $4 \mathrm{p}{ }^{4} \mathrm{P}^{0}$ perturbing levels contributing positively to the shift. The reason for the strong disagreement with our measurements might indicate that $4 \mathrm{p}^{2} \mathrm{P}^{0}$ and $4 \mathrm{p}{ }^{4} \mathrm{P}^{0}$ levels are in fact a combination of different contributions which results in decrease of their influence.

\subsection{Transition probabilities}

Generally, our measured $A$ values are higher by about $19 \%$ on average than the data provided by NIST (NIST 2001).

In the case of the $3 \mathrm{~s}-3 \mathrm{p}$ transition the measured $A$ values (GMW - Griesmann et al. 1997 and BV - Burshtein \& Vujnović 1991) show a tendency to increase in recent years (see Table 1).

We point out here that our four measured A data in the high-lying $3 \mathrm{~d}-4 \mathrm{f}$ transition confirm the existing calculated values obtained by (Wiese et al. 1966; NIST 2001; Kurucz 2001), within 9\%. It turns out that the recent theoretical calculations (Fischer \& He 1999) give different $A$ values which depend on the used approximations. This difference is, for example, in the case of the $3 \mathrm{~d}{ }^{4} \mathrm{P}_{3 / 2}-3 \mathrm{p}{ }^{4} \mathrm{~S}_{3 / 2}^{0}$ transition, up to a factor 3 between the results obtained with the multiconfiguration Hartree-Fock (MCHF) method and the multiconfiguration Dirac-Fock (MCDF) method. Moreover, the calculated and measured $A$ values presented in various data sources (Blackford \& Hibbert 1994) and (Fischer \& He 1999) show mutual discrepancies by up to a factor 100 . 


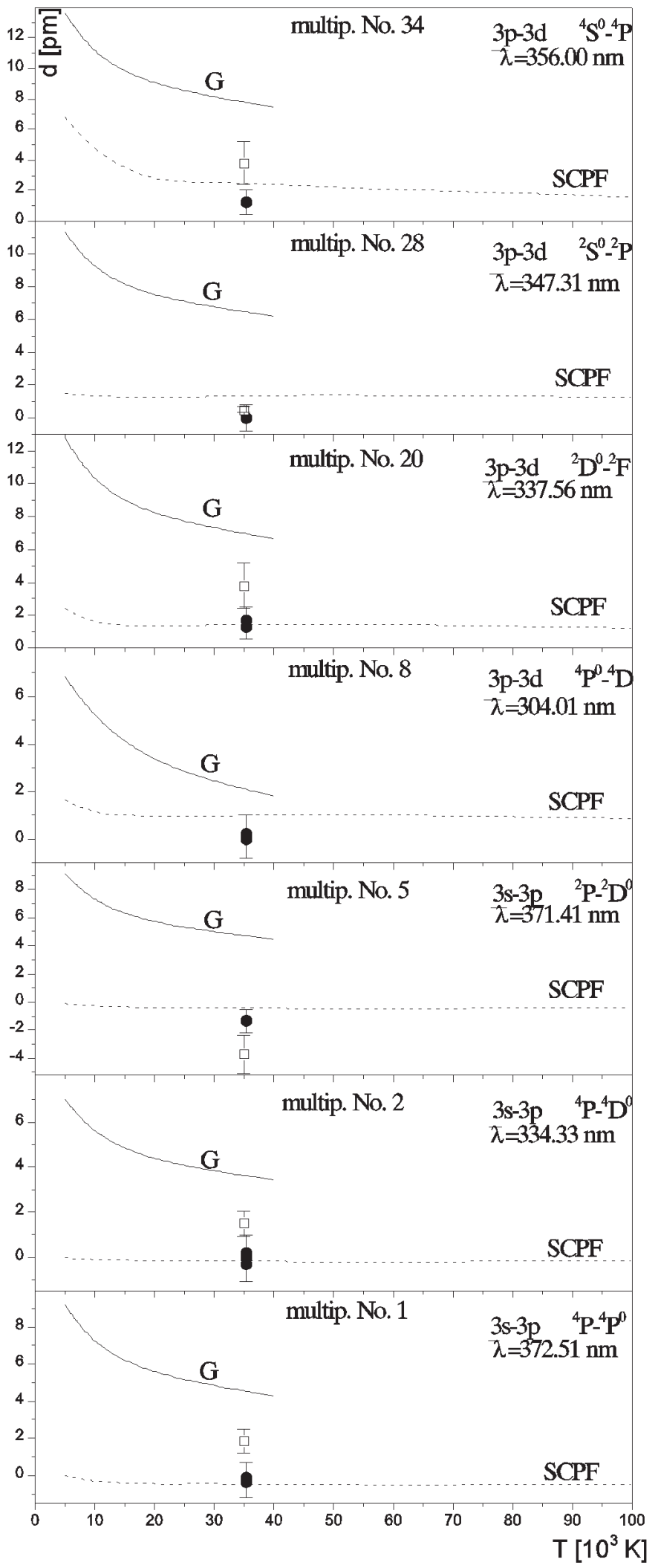

Fig. 5. Stark shift ( $d$ in pm) dependence on the electron temperature for various transitions at $10^{23} \mathrm{~m}^{-3}$ electron density. - our experimental data and $\square$, from Purić et al. (1987). G, theoretical calculations taken form Griem (1974) and our calculated (SCPF) Stark shift values taken from Table 2. The error bars of $\pm 0.0008 \mathrm{~nm}$ represent the uncertainties of the shift measurements. Positive shift is toward the red.

\section{Conclusion}

We have presented in this work experimental Stark shifts for 41 Ne II spectral lines at an electron temperature of $35300 \mathrm{~K}$ and an electron density of $1.83 \times 10^{23} \mathrm{~m}^{-3}$, as well as calculated Stark shift values for 22 multiplets for an electron density of $10^{23} \mathrm{~m}^{-3}$ and for electron temperatures from $5000 \mathrm{~K}$ up to $100000 \mathrm{~K}$. The shift values found are, generally, small. In the case of the $3 \mathrm{~s}-3 \mathrm{p}$ and $3 \mathrm{~s}^{\prime}-3 \mathrm{p}^{\prime}$ transitions they are practically equal to zero. The common characteristics of these $d$ values is the weak dependence on the electron temperature up to $100000 \mathrm{~K}$. Thus, these can be used for diagnostics purposes as data independent of self-absorption in optically thick astrophysical plasmas.

Our measured $A$ values, using the RLIR method, are generally higher than those published by NIST (NIST 2001). The difference is still within our experimental accuracy $( \pm 20 \%)$ and the known uncertainties for NIST values $( \pm 50 \%)$.

Acknowledgements. This work is a part of the projects "Determination of the atomic parameters on the basis of the spectral line profiles" and "Influence of collisional processes on astrophysical plasma lineshapes" supported by the Ministry of Science, Technologies and Development of the Republic of Serbia. S. Djeniže is grateful to the Foundation "Arany Janos Kozalapitvany" Budapest, Hungary

\section{References}

Ashby, D. E. T. F., Jephcott, D. F., Malein, A., \& Raynor, F. A. 1965, Appl. Phys. B: Photophys. Laser Chem., 36, 29

Bashkin, S., \& Stoner, J. O. Jr. 1978, Atomic Energy Levels and Grotrian Diagrams, vol. I (North Holland, Amsterdam)

Blackford, H. M. S., \& Hibbert, A. 1994, At. Data Nucl. Data Tables, 58, 101

Burshtein, M. L., \& Vujnović, V. 1991, A\&A, 247, 252

Davies, J. T., \& Vaughan, J. M. 1963, ApJ, 137, 1302

Dimitrijević, M. S., \& Sahal-Bréchot, S. 1984, JQSRT, 31, 301

Dimitrijević, M. S., \& Sahal-Bréchot, S. 1996a, Phys. Scr., 54, 50

Dimitrijević, M. S., \& Sahal-Bréchot, S. 1996b, A\&AS, 119, 369

Dimitrijević, M. S., Sahal-Bréchot, S., \& Bommier, V. 1991, A\&AS, 89, 581

Djeniže, S., Srećković, A., \& Labat, J. 1992, A\&A, 253, 632

Djeniže, S., Srećković, A., Labat, J., Konjević, R., \& Popović, L. C. 1991, Phys. Rev. A, 44, 410

Djeniže, S., Milosavljević, V., \& Srećković, A. 1998, JQSRT, 59,71

Djeniže, S., \& Bukvić, S. 2001, A\&A, 365, 252

Fischer, C. F., \& He, X. 1999, Can. J. Phys., 77, 177

Fleurier, C., Sahal-Bréchot, S., \& Chapelle, J. 1977, JQSRT, 17,595

Griem, H. R. 1964, Plasma Spectroscopy (New York: McGrawHill Inc.) 
Griem, H. R. 1974, Spectral Line Broadening by Plasmas (New York: Acad. Press)

Griem, H. R. 1997, Principles of Plasma Spectroscopy (Univ. Press Cambridge, Cambridge)

Griesmann, U., Musielok J., \& Wiese, W. L. 1997, J. Opt. Soc. Am. B, 14, 2204

Hey, J. D. 1976, JQSRT, 16, 69

Kurucz, R. L. 2001, Harvard-Smithsonian Center for Astrophysics, CDROM 23

Lesage, A., \& Fuhr, J. R. 1999, Bibliography on Atomic Line Shapes \& Shifts (April 1992 through June 1999) Observatoire de Paris

Maissel, L. I. 1959, Proc. Phys. Soc. London, 74, 97

Mandel'shtam, S. L. 1962, in Optik und Spektroskopie Aller Wellenlängen (Akademie Verlag, Berlin), 372

Mandel'shtam, S. L., Mazing, M. A., Sobel'man I. I., \& Vainshtein, L. A. 1963, Proc. VI Int. Conf. Phen. in Ioniz. Gases, ed. J. Taillet (S.E.R.M.A. Paris, 1963), vol. III, 331

Mazing, M. A., \& Vrublevskaya, N. A. 1962, Opt. Spektrosk. (USSR), XIII, 308

Milosavljević, V., Djeniže, S., Dimitrijević, M. S., \& Popović, L. Č. 2000, Phys. Rev. E, 62, 4137

Milosavljević, V., \& Poparić, G. 2001, Phys. Rev. E, 63, 036404

Moore, C. E. 1971, Atomic Energy Levels, vol I, NS RDSNBS 35 (US Department of Commerce, National Bureau of Standards, Washington D.C)

NIST - Atomic Spectra Data Base Lines (wavelength order) http://physics.nist.gov (2001)
Popović, L. Č., Srećković, A., Djeniže, S. 1992, Proc. 11th ICSLS, A25, Carry le Rouet, France, ed. N. Feautrier et al. (Université de Provence en Marseille, Marseille, 1992)

Pretty, W. E. 1931, Proc. Phys. Soc. London, 43, 279

Purić, J., Djeniže, S., Srećković, A., Labat, J., \& Ćirković, Lj. 1987, Phys. Rev. A, 35, 2111

Quinet, P., Palmeri, P., \& Biémont, E. 1994, Phys. Scri., 49, 436

Rompe, R., \& Steenbeck, M. 1967, Ergebnisse der Plasmaphysik und der Gaselektronik, Band 1 (Berlin: Akademie Verlag)

Sahal-Bréchot, S. 1969a, A\&A, 1, 91

Sahal-Bréchot, S. 1969b, A\&A, 2, 322

Sahal-Bréchot, S. 1974, A\&A, 35, 321

Striganov, R. A., \& Sventickij, N. S. 1966, Tablicy Spektral'nykh linij (Atomizdat, Moskva)

Thieleman, F. K., Nomoto, K., \& Yokoi, K. 1986, A\&A, 158, 17

Trimble, V. 1991, A\&AR, 3, 1

Wiese, W. L., Smith, M. W., \& Glennnon, B. M. 1966, Atomic Transition Probabilities, vol. I, Hydrogen through Neon, NSRDS-NBS4, US Department of Commerce, National Bureau of Standards, Washington D.C

Wiese, W. L. 1968, Methods of Experimental Physics, ed. B. Bederson, \& W. L. Fite, vol. 7B (Academic Press, New York)

Zeippen, C. J. 1995, Phys. Scr., 58, 43 